\title{
A research into cultural identity construction in the history of the Chinese American literature
}

\author{
Yanli Xiang \\ College of Foreign Languages, Ankang University, Ankang Shanxi, 725 000, China
}

Keywords: Identity construction, Creative practice, Cultural collision, Chinese American.

\begin{abstract}
Chinese American literature has distinctive characteristics and features as its production and development is the outcome of cultural collision and fusion between China and America. From analyzing and observing its developmental process, we can find that there contains multiple conflicts and cultural identity construction is the center of all conflicts. The topic this thesis will discuss is the specific process of this cultural identity construction.
\end{abstract}

\section{Introduction}

Social life can be reflected by literature creation and lives of ethnic Chinese in American can be reflected by Chinese American literature, including their adaptive process, and the oppression and exploitation they have suffered [1]. Their cultural identity construction has gone through centuries of development and can be divided into four different phases.

\section{Phase one}

This stage can be summarized as a period of aphasia when ethnic Chinese were not accepted by the mainstream society, but with conceptual images distorted in American works on the basis of Orientalism. The distortion has embodied that Americans regarded as ethnic Chinese as a disparate group or even intruders so that they misunderstood the culture represented by ethnic Chinese. In this phase, it was through the denial of ethnic Chinese and the representative culture to improve the sense of self superiority. Chinese American literature in this period mainly presented that mainstream writers recklessly gave a lot of relevant manifestation that the white race was above all other races so as to cater for current trend of events at that time. It can be seen that literature in this period can only indicate the extreme behaviors Americans have done to images and works of ethnic Chinese in the trend of squeezing out ethnic Chinese. Contents stated above have shown that in this phase Chinese American literature was in an environment of cultural aphasia also with cultural identity lost already[2]. The preliminary stage of cultural identity construction for ethnic Chinese refers to the period when American Caucasians' White supremacy owned absolute power of discourse and the voice authority of the ethnic showed the ethnic status and identity. In the initial stage of cultural identity construction, human races will be divided into two main categories: civilized races and barbarians. Kant has said in "Physical Geography" that, the white race belonged to the most perfect racial model in the world, yellow race and Indian had low IQ, and the black people was lower than the former. Most American tribes had the lowest level of IQ. Fehn has differentiated Americans' attitude towards ethnic Chinese into several phases, generally called as Chinese invasion period. The first phase was tolerant phase; the second phase was adverse phase; the third phase was restricted phase. Therefore, the preliminary time of ethnic Chinese's cultural identity construction in America was a time when the mainstream society represented by American white people distorted or deliberately destroyed ethnic Chinese culture and even slaughter ethnic Chinese. For example, United States 
Congress passed a resolution "Chinese Exclusion Law"; the event of slaughtering Chinese happened in Denver in 1880; in 1887 seven white gangsters fiercely beat 10 Chinese workers to death. All of these cases were exact factual proofs of Caucasian dominance then. The white people have once praised themselves as the symbol of world civilization, and Savior and guardian of barbarians and backward races so that they thought their culture as the most vigorous and lively culture in the world. But ethic Chinese were deadly silent, incorrigible and vicious, and even crude so the culture they presented together with them were evil and savage, which would finally decline and vanish. Jack London, American short-story writer has insinuated and slandered Chinese in his novels. Hart has faked the Chinese image into Ah Sin who looked simple, loyal and honest giggling all the time but good at lying and using dishonest means. Ah Sin was described as a heretic Chinese using heterodoxy. So in American white people's eyes, Chinese people no matter men or women could only do housework just for women.

In many American writers' articles, ethnic Chinese are described as incurable heretics addicted to wine and women all day with funny looks acting as loyal servants to their masters. Chinese representative Confucian culture symbolized backwardness, cowardice and modesty. Chinatown, the place Chinese lived in America was the origin of darkness and evils, such as the initiator of evil described in "Chinatown Collection" in 1892. All of these descriptions were how American white people and even Westerners view Chinese and their distorted imaginations. Descriptions of Chinese by American white people in the mainstream society changed from romantic imagination to sarcasm and vituperation, which fundamentally denied ethnic Chinese and their representative cultures. These stingers gained racial superiority complex from their own articles or languages.

For example, in the article "Chinese get back" written by a writer Henry Graeme of this time, some disgusting and dreadful words were used to slander and abuse Chinese people. It can be seen that ethnic Chinese group in the early period of Chinese American literature was in a silent state of racial oppression. Meanwhile, it was also the starting point of the cultural identity construction in Chinese American literature, and a time when Chinese American writers rebelled the absolutely racial power to get themselves heard by the whole world so as to break the cultural language in the mainstream society of white people and to gradually step to the top from the bottom of the hierarchy.

\section{Phase two}

This phase is the period starting constructing cultural identity, generally summarized as the stage of identity. It can be specifically divided into two different periods. The difference lies in the affirmation and negation of identity in the ethnic. And affirmation is prior to negation.

During the process of constructing cultural identity, national features take up very important position specifically including culture, language and history. Breaking the silence is a very important and the first step for cultural identity construction. Speak out the voice of ethnic Chinese and try to transform fantasies and imaginations of the mainstream culture and break through powerful voices of racialism. The first Chinese American writer to voice for ethnic Chinese was Edith Eton who spoke out with her pen to break through the silence and made positive efforts for defend ethnic Chinese. To take a stand for Chinese culture, she has extensively searched for Chinese stories and integrated these elements into the creation of her short novels. Her creations have played certain roles in changing the distorted images of Chinese. Regarding the belief, Edith Eton pointed out that although unfortunate ethnic Chinese were not follower of Jesus, they who lived in lively communities had their own ideas and beliefs. Emotionally, she advocated that from the perspective of mainstream society there exist obvious differences in lives of Ethnic Chinese, they had much more delicate emotions and more sensitive problem-solving methods and there was no difference with white people in the abundance of emotions. Regarding the language, oppression was the main reason of the ethnic Chinese silence instead of incorrigible stubbornness. Not being accepted by the mainstream society was an important cause leading to Ethnic Chinese's Pidgin English. "Mrs. Spring Fragrance" as one of her representatives, attempted to overturn the mainstream voice through the description of family life of ethnic Chinese. In a word, Edith Eton has denied the concept of mainstream racial ascendency and 
affirmed the identity of ethnic Chinese through the way of literature creation, which had awakened the cultural and ethnic consciousness of ethnic Chinese.

Afterwards, more and more Chinese American writers joined the construction of cultural identity, more and more voices were spoken out and ethnic consciousness was strengthened. The first Chinese American writer who had widespread influence was Tang Tingting. She has criticized racial discrimination and Chinese patriarchy at the same time in her book "The Woman Warrior" from the perspective of ethnic feminism. Although the critique was mainly on the former, Asian critics thought

this article was to cater for the Oriental views at that time ${ }^{[3]}$. It could be said that the effect of this novel was bidirectional and meanwhile it could reflected that sublation or processing ethnic culture was one part of cultural identity construction helpful to reduce the misunderstanding. Another example of this bidirectional lashout was Zhao Jianxiu whose manifestation had stand out in the book "Year of the Dragon". The play inveighed oppression and discrimination but also sneered the ethnic Chinese's persistence of Chinese culture after immigration. The bi-directional attack had double-faced effects. On one hand it formed powerful shock to the conceptual images at that time, and on the other hand, it denied Chinese culture and meanwhile did not provide new images and new support. Characters in his article, full of resistant emotions for the racial discrimination in the environment, had a hatred attitude toward Chinese culture as they were not accepted by the mainstream society so that they were self-lost. This kind of thinking and exploration in a confusing state promoted the development of cultural identity construction.

\section{Phase three}

This phase could be summarized as the exploration period with the main characteristic of affirming Chinese culture's function in the exploration period. The specific time was in 1980s and 1990s when the foundation of Chinese American literature was established. During this period, Zhao Jianxiu's creation experienced experience periods of high and low tide. In the period of low tide, he still criticized behaviors that Tang Tingting distorted Chinese culture. After entering the period of high tide, Zhao Jianxiu successively created new works, all of which were about exploring identity construction. In "Donald Duk", the leading character looked up in library to testify that Chinese were faster than British in building railways. This brought back dignity and self-ego making him proud in his own ethnic. The discovery of cultural root finally helped him get rid of the confusing condition. In "Gunga Din Highway", Zhao Jianxiu criticized the internalization of White Supremacy and ethnic Chinese who praised American style. He emphasized that ethnic Chinese should have their own national and independent awareness, and never should be second-class citizens. Meanwhile, he also proposed some specific methods for ethnic Chinese people to be independent. Two cultures had their own advantages and flaws. On one hand, learned to abrogate and on the other hand absorbed nutrition from them. New type sensibility was the achievement of his arduous exploration with the evaluation standard of neither Chinese culture nor American mainstream culture but with the history of Chinese Americans as the basis. For a long time in American mainstream culture, the conceptual image of ethnic Chinese was mainly embodied as yellow peril and servant. So to achieve a new type sensibility, should start from denying this false mage never faking Chinese culture flattering white people or catering for their curiosity. In a work, the establishment of new cultural identity should be based on the real-world environment and to stick to own characteristics in American cultural creation.

Meanwhile, Tang Tingting never stopped her exploration. The creation of "China Men" was the make-up of her previous negative description of Chinese culture. In the book, the immigrated Chinese men contributed great to new land as a member to promote American economic development with the identity of equal status with white people. They were worthy of being respected and their culture should not be hostilely attacked. In the book "Tripmaster Monkey", she also discussed the issue of identity construction for ethnic Chinese ${ }^{[4]}$. The leading character in the book was the presentation of cultural fusion with multiple identities so that it was hard to tell his culture or ethnic. He was not an 
ethnic Chinese image in mainstream perspective, or a Chinese cultural image. Although he was a Chinese young man, he had American characteristics.

Amy Tan was also a representative writer at that time who had positively discussed the issue of cultural identity consruction mainly reflected in her novel creation. David Henry Hwang has also made exploration on the possibility of ethnic identity after long-time pondering. Assimilation, nationality and fusion were main clues of his thinking development. "Fresh off the boat" and other dramas reflected the assimilation period; "Family devotions" reflected the nationality period with the main contents of criticizing Christian's attempt of brainwashing; "Golden child" reflected the integration and fusion period mainly to rebuild the identity of ethnic Chinese with a mixing method.

\section{Phase four}

This phase can be concluded as the mixed identity in ethnic scattered living. In the exploration period, the foundation of ethnic Chinese writers to construct cultural identity was American culture or Chinese culture and it entered into a new thinking period in the latter half of 1990s. Gish Jen was the representative writer in this period whose exploration was never restricted to common topics such as cultural conflicts, myths and legends, etc. but to redefine American people and their culture with the focus on multi-culture. In her opinion, American was defined as people who lived in America and American culture was formed by multiple nations and ethnics ${ }^{[5]}$. Therefore, her text creation was the breakthrough of binary opposition logic. In the book "Typical American", Chinese student Ralph Zhang gradually became a typical American after living there. He adapted to the game rules in this country very quickly. The book showed the process of Chinese people accepting American culture and adjusting their endeavor direction correspondingly under the cultural influence so that they had American standard and dreams ${ }^{[6]}$. Her description of Mona in "Mona in the Promised Land" further displayed her multi-cultural concept. In the book "Who's Irish?", two different ethnics gathered together due to the establishment of a marriage. At first it was hard for both to accept the other's living style, but the cultural conflict shaded away with the closer relationship between each other and the deepening of influence from each other so that their ethnic identities were forgotten by Chinese and Irish, hard to tell. The creation perspective of these contexts had huge breakthroughs further promoting the construction of cultural identity and discussing the fusion between American mainstream society and ethnic Chinese from specific works. Mixed identity was the main feature in this period to help ethnic Chinese to settle down their identity crisis with a new way out.

\section{Conclusion}

The history of Chinese American literature has included different aspects of contents such as the critic on racial discrimination, the compliant for exploitation and oppression, and positive exploration during the process of constructing cultural identity and some errors. The creation by ethnic Chinese writers was the overturn of conceptual image of ethnic Chinese at that time, the deconstruction of authoritative voices, and long-time thinking of identity construction. It is the construction to achieve self identity with the method of cultural and theoretical support.

\section{Reference}

[1] Panfei. Construction of Chinese and Western cultural fusion vision in Chinese American literature,Journal of Zhejiang University Science and Technology, 2016(02):101-105.

[2] Hu Beike. Cultural characteristics of Chinese American literature and the time evolution, Journal of Northeast Normal University, 201, 6(01):17-21.

[3] Xiao Hua. Position of ethnic Chinese-patriarchal ideology in Chinese American literature, family and national summon, and the creation context and expecting view, Chinese Literature, 2015 (03):92-103. 
[4] Yan Bihong, Zheng Jing, Wei Ting. Deconstruction and construction: Misreading of Chinese culture in the works of Maxine Hong Kingston, Journal of Jixi University, 2016 (06):131-134.

[5] Liu Lina. Discussion on the transition of identity appeal in Chinese American literature- with Maxine Hong Kingston, Jade Snow Wong and Gish Jen, as examples, Northern Literature, 2015(04):52-53.

[6] Chen Xi, Lin Xiaowen. Discussion on the new image of ethnic Chinese man, Ralph Zhang in "Typical American", Journal of Luohe Vocational Technology College, 2016 (01):37-40. 